\title{
Introduction: Digital Human Sciences as a Field of Research
}

Sonya Petersson and Uno Fors

The ongoing digitization of culture and society and the ongoing production of new digital objects in culture and society require new ways of investigation, new theoretical avenues, and new multidisciplinary frameworks. In order to meet these requirements, this volume digs into questions concerning, for example: the epistemology of data produced and shared on social media platforms; the need for new legal concepts that regulate the increasing use of artificial intelligence in society; and the need for combinatory methods to research new media objects such as podcasts, web art, and online journals in relation to their historical, social, institutional, and political effects and contexts. Gathered around the perspective of what we call digital human sciences-a field of research that includes the humanities, the social sciences, and lawthe chapters in this volume emanate from scholars situated within a broad range of disciplines. Nevertheless, they meet in the mutual objectives of researching the present digitization of culture and society and of discussing ways of doing research within this field of study.

\section{Purpose of the Volume}

Our purpose is twofold. First, we aim to discuss and develop methods and approaches for investigating digital society, digital culture, and digital media objects. Second, we aim to develop the new research field of the digital human sciences through the methodological discussion.

How to cite this book chapter:

Petersson, Sonya, and Uno Fors. "Introduction: Digital Human Sciences as a Field of Research." In Digital Human Sciences: New Objects-New Approaches, edited by Sonya Petersson, I-20. Stockholm: Stockholm University Press, 202I. DOI: https://doi.org/IO.I6993/bbk.a. License: CC-BY. 
Our definition of digital human sciences is inclusive. "Digital human sciences" describes a multidisciplinary field of research aimed at the study of digital objects and environments and their significance for human beings and society. This includes, but is by no means limited to: investigations of agents and their roles in digital society; social and legal aspects; questions of liability and ethics; and interaction between human beings in digital systems and between human beings and digital entities. The field of the digital human sciences thus transgresses not only disciplinary borders but also borders between faculties (the humanities, the social sciences, and law). It could include objects of study such as internet history, online museums, computer games, social tweeting practices, AI systems in public administration or medical service, and web forums for political activism.

The question now is how we methodologically approach such topics and objects of study. Do they require a combination of digital tools and traditional close reading, a fusion of philosophical reasoning and web archaeology, or media theory, traditional sociology, and digital epistemology in a sort of union with contributions from law and information technology too? What kinds of exchanges over traditional disciplinary borders are beneficial for methodological developments and experiments? Where are the dividing lines between material infrastructure, intellectual infrastructure, and methodological procedures, and how should they be dealt with?

Each chapter both reflects on these types of general methodological questions and concretizes them in a particular case study. The volume is thus tied together by the running methodological discussion, while its particular cases are built around the diversity and specificity of social, cultural, medial, and legal objects, discourses, and practices in digital culture and society.

\section{Beginnings}

This volume is one of the results from the digital human sciences initiative at Stockholm University in 2016. A group of scholars from the humanities, social sciences, and law faculties was then appointed to form a committee for promoting, funding, and organizing research activities around the study of digital culture 
and society. ${ }^{\mathrm{I}}$ Initially, one of the central tasks was to map out the field. What is meant by "digital human sciences," what types of research objects and topics does it circumscribe, and how does it overlap with or depart from related fields of research? While the definition above sheds light on the first two questions, the third question will be addressed in the next section.

\section{Digital Human Sciences and Related Fields of Research}

The field of the digital human sciences is part of what is often and in the broadest sense referred to as digital studies. We align our project to the general objective of Arthur and Marilouise Kroker in the introduction to the by now classic reader Critical Digital Studies, as it encourages investigating culture and society in relation to:

the potential of digital devices for shaping the ways in which we understand the world and communicate with one another to the unexplored implications of technological innovations-mobile media, cloud computing, social networking, augmented reality, ${ }_{3} \mathrm{D}$ printing, drone technology_for both illuminating and, perhaps, sometimes constraining the human condition. ${ }^{2}$

As much as we subscribe to the importance of examining the various ways in which digital culture and society inflect the "human condition," we nevertheless avoid the term "digital studies." Its umbrella character could too easily be confusing. ${ }^{3}$ First of all, it is often invoked in relation to academic milieus, infrastructures, and research output that could just as well and more aptly be related to the digital humanities. This is, for instance, the case when

I See the Digital Human Sciences website for more information: https:// dhv.blogs.dsv.su.se. The Digital Human Science Committee at Stockholm University 2016-20 included Uno Fors and Petter Karlström from the Department of Computer and Systems Science, Cecilia Magnusson Sjöberg from the Department of Law and Informatics, and Christer Johansson and Sonya Petersson from the Department of Culture and Aesthetics.

2 Arthur Kroker and Marilouise Kroker, eds., "Introduction," in Critical Digital Studies (Toronto: University of Toronto Press, 20I3 [2008]), 3.

3 Cf. Bernard Stiegler's all-embracing use of the term in "Call for Digital Studies," paper composed in 2012, Digital Studies Network website, https://digital-studies.org/wp/call-for-digital-studies/. 
universities in the Anglophone world use the label "digital studies" for programs and courses that teach computing skills in the context of culture, the arts, and the humanities. ${ }^{4}$ The same is true of the scholarly journal Digital Studies/Le Champ numérique, published for the Alliance of the Digital Humanities Organizations. ${ }^{5}$ Its French parallel title is further evocative of what Camille Roth calls "numerical humanities" and characterizes as a subfield of the digital humanities employing quantitative research methods. ${ }^{6}$

Moreover, the label "digital studies" could also very well include many of the other fields of research that intersect with and inform the digital human sciences: software studies, new media studies, human and computer interaction, digital cultural heritage, and — to a certain extent—media archaeology. 7 The hesitation about media archaeology has to do with how "the digital" sometimes enters and functions within the field. Whereas, for instance, studies of digital cultural heritage generally investigate the digital preservation, storage, and accessibility of art and cultural artifacts, media archaeology is often inclined to treat "the digital" as an interface to which previous (and future) media are

4 E.g., “The Digital Studies MA,” Chicago University website, https://digital studies.uchicago.edu/about/digital-studies-ma; "Digital Studies Certificate Program,” Northwestern University website, https://sps.northwestern.edu /advanced-graduate-certificate/digital-studies/; "Digital Studies in the Arts and Humanities," University of Maryland website, https://dsah.umd.edu/; "Digital Studies," University of Pittsburgh website, https://www.greens burg.pitt.edu/academics/majors-minors/digital-studies; "Digital Studies," University of Wisconsin-Madison website, https://digitalstudies.wisc.edu.

5 "About this Journal," Digital Studies/Le Champ numérique website, https://www.digitalstudies.org.

${ }^{6}$ Camille Roth, "Digital, Digitized, and Numerical Humanities," Digital Scholarship in the Humanities 34, no. 3 (2019): 617-6I9.

7 See, e.g., Matthew Fuller, ed., Software Studies: A Lexicon (Cambridge, MA: MIT Press, 2008); Mark B. N. Hansen, Feed-Forward: On the Future of Twenty-First-Century Media (Chicago, IL: University of Chicago Press, 20I 5); Johanna Drucker, Graphesis: Visual Forms of Knowledge Production (Cambridge, MA: Harvard University Press, 2014); Oliver Grau, ed., Imagery in the $2 I^{\text {st }}$ Century (Cambridge, MA: MIT Press, 20I3); Yanni Alexander Loukissas, All Data Are Local: Thinking Critically in a Data-Driven Society (Cambridge, MA: MIT Press, 20I9); Erkki Huhtamo and Jussi Parikka, eds., Media Archaeology: Approaches, Applications, and Implications (Berkeley, CA: University of California Press, 20II). 
interconnected. In the first case, "the digital" is an integrated part of the object of study. In the second case, it functions as a sort of lens-often in terms of the Foucauldian "archive" - through which the object of study (digital as well as analog media) is remediated and excavated. ${ }^{8}$ This difference is pivotal to the digital human sciences and will be further discussed below.

\section{Digital human sciences and digital humanities}

As indicated above, the field of digital human sciences connects to the by now well-established field of digital humanities. The latter is a body of research that is far-reaching, inclusive, under constant development, and admittedly hard to pin down in a few sentences. ${ }^{9}$ By calling it a field, we follow what we take to be the point of Blackwell's New Companion to Digital Humanities, which originally appeared in 2004 and reappeared in a new edition in 2015 . The new edition reassesses the first edition's consideration of digital humanities as a "discipline in its own right." Instead, the editors speak of a field:

It remains debatable whether digital humanities should be regarded as a "discipline in its own right," rather than a set of related methods [...]. In retrospect, it is clear that the decision this group

${ }^{8}$ Cf. Jussi Parikka, What Is Media Archaeology? (Cambridge: Polity, 2OI2), II3-I35.

9 For the diversity and evolving character of the field, see: Barbara Bordalejo and Roopika Risam, eds., "Introduction," in Intersectionality in Digital Humanities (Leeds: Arc Humanities Press, 20I9), I-8, for questions about how social identity intersects the digital humanities and challenges its traditional "big tent" metaphor; Stuart Dunn and Kristen Schuster, eds., "Research Methods in the Digital Humanities: General Introduction," in Routledge International Handbook of Research Methods in Digital Humanities (London: Routledge, 2020), I-9, for the important question of how "methodology grounded in negotiation" (as distinct from reconciliation) ties together idiographic and nomothetic fields of research and thus moves beyond interdisciplinarity only among humanists; and Agiati Benardou et al., eds., "Introduction: A Critique of Digital Practices and Research Infrastructures," in Cultural Heritage Infrastructures in Digital Humanities (Abingdon, Oxon: Routledge, 20I 8), I-I 4, for an argument developing a view of digital infrastructures as "ecosystems" both by their own evolving nature and by their use beyond the academy, in the cultural heritage sector at large. 
of editors, prompted by their publisher, took in naming the original Companion changes the way we refer to this field: we stopped talking about "humanities computing" and started talking about “digital humanities.”

We understand "discipline" to target established and by tradition and institutional infrastructures' more fixed spheres of knowledge, such as art history, comparative literature, computer and systems science, and so on, while "field" is a more flexible denomination. Fields could be held together by related objects of study, related research perspectives, or, to take the example from the quote, related methods, which all have the function of uniting scholars otherwise working in different disciplines. ${ }^{\text {II }}$ In this respect, the digital human sciences are, just like the digital humanities, a field of research. But in two specific regards the digital human sciences depart from the digital humanities: the one concerning that which holds the field together- "a set of related methods" versus the object of study-and the other concerning the transgression of faculty borders.

First, the digital human sciences take as their object of study the ongoing digitization of culture and society, including the relations between digital entities and human beings, while the digital humanities do not necessarily construe the object of study in digital terms. Instead, the digital humanities are broadly associated with employing digital tools to deal with their objects of study and with a narrower history of computational text analysis. The latter is usually exemplified by Roberto A. Busa's (printed) Index Thomisticus, the result of a computational processing of Thomas

ro Emphasis added. Susan Schriebman, Ray Siemens, and John Unsworth, eds., "Preface," in A New Companion to Digital Humanities (Chichester: John Wiley and Sons, 2016 [2004]). For a different account of the Companion's role in the formation of the digital humanities as a field, see Matthew Kirschenbaum, "What Is Digital Humanities and What's It Doing in English Departments?" in Debates in the Digital Humanities, ed. Matthew K. Gold (Minneapolis, MN: University of Minnesota Press, 20I 2), 4-5.

I Cf. Janina Wildfeuer et al., eds., "Multimodality: Transdisciplinary Thoughts and the Challenge of Diversity - Introduction," in Multimodality: Disciplinary Thoughts and the Challenge of Diversity (Berlin: De Gruyter, 2019), I6-2I. 
Aquinas's writings in search for word stems that began in the I940s. A similar endeavor is the text corpora Press-65, developed during the I960s by the Swedish linguist Sture Allén. ${ }^{\mathrm{I2}}$

As for the contemporary digital humanities' emphasis on digital tools, the core tendency is to highlight the intersection of the various disciplines of the humanities and "the digital" as residing in the methodological and epistemological scholarly engagement with digital technologies and infrastructures as instruments of research. New and (often) creative ways of employing digital tools for humanist ends are hailed as reconfiguring older epistemologies, as enabling new research questions, and as paving the way for multimodal rather than predominately textual representations of knowledge. ${ }^{13}$ Differently put, "the digital" is conceived of as standing in a more or less instrumental relation to the humanities; it is a tool of research, but not necessarily an object of research. ${ }^{\text {I4 }}$ This is why distinguished digital humanities scholars such as David M. Berry and Anders Fagerjord, as well as Patrik Svensson, stress

${ }^{12}$ For more information on Press-65 and Språkbanken (the language bank), hosted by Gothenburg University, see Lars Borin, “About Språkbanken,” Språkbanken website, https://spraakbanken.gu.se/eng/about-us/about -spr\% $\mathrm{C}_{3} \% \mathrm{~A}_{5}$ kbanken. See also Koraljka Golub et al., "Digital Humanities in Sweden and Its Infrastructure: Status Quo and the Sine Qua Non," Digital Scholarship in the Humanities 35, no. 3 (September 2020): $547-556$.

I3 Cf. Katherine N. Hayles, How We Think: Digital Media and Contemporary Technogenisis (Chicago, IL: University of Chicago Press, 2012), 23-79; Patrik Svensson and David Theo Goldberg, eds., "Introduction" and "The Field of Digital Humanities," in Between Humanities and the Digital (Cambridge, MA: The MIT Press, 2015), I-I6; Patrik Svensson, Big Digital Humanities: Imagining a Meeting Place for the Humanities and the Digital (Ann Arbor, MI: University of Michigan Press, 2016); Stefan Gelfgren and Julia Pennlert, "En (digital) humaniora? Potential, dilemma och kritik," in Digital humaniora - Humaniora i en digital tid, eds. Per-Olof Erixon and Julia Pennlert (Gothenburg: Daidalos, 2017); David M. Berry and Anders Fagerjord, Digital Humanities: Knowledge and Critique in a Digital Age (Cambridge: Polity Press, 20I7).

${ }^{14}$ More precisely, digital research tools are often argued to indirectly both embrace and transgress mere instrumentality, exactly because of the digital humanities' recognition of their mutual effects on the objects of study and the process of knowledge production. Cf. Benardou et al, “Introduction," 3, 5. 
the need for keeping a sharp focus on research questions originating in the humanities even if elaborated and inflected by the use of digital tools. ${ }^{15}$ This point is actually a part of the field's growing ambivalence toward, and critical reconsideration of, the effects of its embracing of digital methods of investigation, collaboration, representation, and distribution of research output. One concern is that the focus on tools and technologies has resulted in weakening the role of the particular research questions of the different disciplines of the humanities. Another is that the focus on digital tools and technologies risks overemphasizing efficacy, large-scale projects, and easy dissemination, and may therefore come to serve neoliberal, administrative, or managerial agendas before scholarly aims. ${ }^{16}$ In the present volume, both Amanda Wasielewski's and Teresa Cerratto Pargman and Cormac McGrath's chapters treat these issues in the contexts of computational methods in art history and learning analytics in higher education. In this regard, both chapters exemplify how the digital human sciences and the digital humanities overlap despite fundamental differences.

As distinct from the digital humanities, the digital human sciences may or may not systematically employ digital tools and technologies as instruments of research, or they may do so to a greater or lesser extent. From the digital human sciences point of view, instruments of research cannot define the field, ${ }^{17}$ especially

I5 Berry and Fagerjord, Digital Humanities, 50; Svensson, Big Digital Humanities, 26. The same spirit informs Eileen Gardiner and Ronald G. Musto's dissociation of digital humanities from humanities computing: "Our perspective in these pages, however, is not with humanities computing, but with the digital humanities, with harnessing computing power to facilitate, improve, expand and perhaps even change the way humanists work." Computational tools are thus turned to humanistic endsperhaps with the effect of altering them, but nonetheless working in their service. Eileen Gardiner and Ronald G. Musto, The Digital Humanities: A Primer for Students and Scholars (Cambridge: Cambridge University Press, 201 5), 4-5.

I6 Svensson and Goldberg, "The Field," ro; Richard Grusin, "The Dark Side of the Digital Humanities: Dispatches from Two Recent MLA Conventions," differences: A Journal of Feminist Cultural Studies 25, no. I (2OI 4): 79-92; Berry and Fagerjord, Digital Humanities, 7, 56-57, I4I.

7 Notwithstanding the fact that many digital humanities scholars define their field in terms of digital tools and technologies as instruments of research, the field cannot be reduced to solely a set of digital methods. It 
since today, in all areas of study, it is hard to imagine scholars working completely without digital tools, systematically employed or not. That said, the scholarly use of digital tools and technologies should still be recognized in its complexity. Especially since a good deal of the tools and technologies in academic practices are somewhat "hidden," naturalized, or functioning as what Matthew Fuller and Andrew Goffey call "gray" media. The latter include media technologies normally unnoticed by human perception-such as algorithms-or so habituated that they are not always recognized as mediating devices in their own rightsuch as databases and workspaces. ${ }^{18}$ Therefore, the lesson to be learned from the digital humanities' highlighting of the use of digital tools and technologies is to be suspicious of media naturalization. When the explicit employment of digital tools, technologies, and infrastructures is made salient by being under scrutiny and exploration, these discussions can by extension serve to also uncover and illuminate the infrastructures and technologies operating in the "gray" domain.

So far, we have outlined the first principal difference between the digital human sciences and the digital humanities, in terms of the former's emphasis on the present digitization of culture and society as the object of study (with digital as well as analog methods) and the latter's emphasis on digital tools. The second difference is that the field of the digital human sciences casts its net on the level of faculties and includes the humanities, the social sciences, and law, while the digital humanities traditionally include the disciplines of the humanities. ${ }^{19}$ Berry and Fagerjord

obviously includes much more, such as critical theory and collaborative infrastructural projects between the academy, the art world, and the cultural sector at large. Cf. Bordalejo and Risam, "Introduction"; Benardou et al., "Introduction"; Kathryn Brown, ed., The Routledge Companion to Digital Humanities and Art History (New York: Routledge, 2020).

${ }^{18}$ Matthew Fuller and Andrew Goffey, Evil Media (Cambridge, MA: MIT Press, 20I2), I, II-I3. See also Loukissas, All Data Are Local, 55-88 for a related discussion of how digital visualization "can help us see data rather than seeing through them" (82) in the context of library collections migrating online.

${ }_{19}$ As in note 17 , while we maintain that the predominance of the arts and humanities in digital humanities is a strong tendency in terms of tradition, the field cannot be reduced solely to this tradition. Artistic practices-as 
manage to put the research activities of a wide-reaching field succinctly: The digital humanities are, "broadly speaking, the application of computation to the disciplines of the humanities." ${ }^{\circ}$ The most important point is not, however, which particular disciplines are contained in the humanities or whether the social sciences or the faculty of law are included in the digital humanities traditionally conceived. Instead, the all-important point is how to conceive of issues of multidisciplinarity and its cognate, interdisciplinarity. Again, there are good reasons to learn from the experiences of the digital humanities, since they have a history of scholarly collaborations on multiple levels. This includes the basic transgression of the boundary between the humanities and systems science/ engineering and, as Patrik Svensson keeps emphasizing, a "liminal" position between the various disciplines of the humanities. ${ }^{21}$ Svensson describes this position as simultaneously a question of material infrastructure (including digital platforms for multidisciplinary journals and research organizations) and a question of intellectual infrastructure-that is, knowledge production benefiting from input from more than one discipline. ${ }^{22}$

\section{Multidisciplinarity, interdisciplinarity, and transdisciplinarity}

The distinction above between material and intellectual multi- or interdisciplinary infrastructures points both to their interdependence and to a pressing need for further distinctions. First, what

distinct from the study of the "arts" in arts and humanities-are occasionally included, as in Thomas Bartscherer and Roderick Coover, eds., Switching Codes: Thinking Through Digital Technology in the Humanities and the Arts (Chicago, IL: University of Chicago Press, 2OII), as well as the social sciences and the legal domain, which is evident from Roth, "Digital, Digitized, and Numerical Humanities"; Alex H. Poole and Deborah A. Garwood, "Digging into Data Management in Public-Funded, International Research in Digital Humanities," Journal of the Association for Information Science and Technology 7I, no. I (January 2020): 84-97; Ryan Whalen, ed., Computational Legal Studies: The Promise and Challenge of Data-Driven Research (Cheltenham: Edward Elgar Publishing, 2020).

${ }^{20}$ Berry and Fagerjord, Digital Humanities, 3.

${ }^{21}$ Svensson, Big Digital Humanities, 33.

${ }^{22}$ For a broader view on research infrastructures/infrastructures for research, see Benardou et al., "Introduction," and comments in previous note 9. 
is the difference between multi- and interdisciplinary approaches? Second, to qualify knowledge as multi- or interdisciplinary, is it enough that it is the product of scholars with different disciplinary backgrounds sharing the same platforms? And, third, are there slight or radical differences between knowledge resulting from a mixture of inputs from different disciplines and knowledge resulting from employing a method from another discipline?

Julie Thompson Klein's definitions of multi- and interdisciplinary collaborative and/or intellectual encounters over traditional disciplinary boundaries are helpful in qualitatively distinguishing between the different sorts of knowledge output these encounters provide. Interdisciplinarity concerns the "integration of information, data, methods, tools, concepts and/or theories from two or more disciplines or bodies of specialized knowledge." ${ }_{23}$ The key issue here is the "integration" of knowledge units as fostering a "more holistic understanding of a question, topic, theme, or problem by individuals or teams." ${ }_{24}$ Interdisciplinarity differs from multidisciplinarity, which concerns the "juxtaposition of separate disciplinary inputs" and "fosters breadth of knowledge and diversity of approaches." ${ }_{25}$ Consequently, multidisciplinary approaches are additive; separate units of knowledge are assembled rather than integrated around a core question.

As a field, the digital human sciences are multidisciplinary. They tie together scholars or groups of scholars from various disciplines in the humanities, the social sciences, and law. Also, the present volume should, on an overarching level, be characterized as a multidisciplinary, collective knowledge output, as it gathers scholars from, for instance, art history, computer and systems science, law, library and information science, and media and communication studies. Within this multidisciplinary venue, many of the contributions additionally have an interdisciplinary approach to their subjects. Johan Jarlbrink's chapter integrates ethnographic perspectives and digital forensics against a backdrop

${ }^{23}$ Julie Thompson Klein, Interdisciplining Digital Humanities: Boundary Work in an Emerging Field (Ann Arbor, MI: University of Michigan Press, 2015), I 5 .

${ }_{24}$ Klein, Interdisciplining, I 5.

${ }_{25}$ Klein, Interdisciplining, I 5 . 
of media and communication studies. Stanley Greenstein and Cecilia Magnusson Sjöberg respectively build their cases around the integration of digital informatics and law. And Teresa Cerratto Pargman and Cormac McGrath's chapter is the result of mixing perspectives from education and computer and systems science.

Since all contributions deal with the same question-about methods and approaches to digital objects and phenomena in culture and society-there is yet another relation between disciplines to consider. In our chapters, the shared question gets repeatedly reset and revisited by different disciplinary or interdisciplinary frameworks. Hence, the question is transdisciplinary in character. The latter differs both from interdisciplinarity and multidisciplinarity in, still according to Thompson Klein, designating "an overarching synthesis associated with new conceptual frameworks." ${ }^{26}$ In this holistic sense, "the digital" in the digital humanities would be the transdisciplinary object per se, as the common denominator of the field. We, however, understand this sense of transdisciplinarity to be too reductive. Our ambition is rather to acknowledge the various reconfigurations that occur in (inter)disciplinary studies of a shared problem, concept, or other object of research. Our sense of transdisciplinarity thus comes closer to Mieke Bal's theory of conceptual travels, which emphasizes "negotiation," "transformation," and "reassessment" on each stage of a concept's trajectory through different (inter) disciplinary frameworks. ${ }^{27}$

All in all, our shared question is transdisciplinary in its travel through the different chapters of this multidisciplinary volume. In each chapter, the question is subjected to an (inter)disciplinary framework that treats it differently and answers it differently.

\section{Outline of the Volume}

The volume is structured in three parts, following the chapters' approaches to the question of how the present digitization of culture and society is submitted to, as well as giving rise to,

${ }^{26}$ Klein, Interdisciplining, 20.

27 Mieke Bal, Travelling Concepts in the Humanities: A Rough Guide (Toronto: University of Toronto Press, 2002), 39. 
methodological and epistemological strategies and constraints. In the first part, the chapters turn toward consequences of method or the types of knowledge and results that emanate from different research practices. In the second part, the chapters have in common their approach to method as being an object of study in itself, in discussions that critically assess how personal data processing methods are employed and functioning in digital society. In the third part, the chapters are concerned with demonstrating method in examinations of digital objects.

\section{Epistemologies of objects, methods, and research practices}

Part one comprises five chapters that examine the different ways in which digital objects, analog as well as digital methods of investigation, and other research practices, condition and inflect knowledge outputs.

First out, Jonas Andersson Schwarz discusses digitally mediated and socially networked texts, exemplified by Twitter conversations. Andersson Schwarz's chapter offers the concept of "social big data" as a shorthand for the complex nature of an information entity ("data") that is semiotic as well as material, and socially situated on the individual as well as on the institutional level, besides being retrievable in enormous quantities ("big”). Another of Andersson Schwarz's points is that such data is not only socially mediated by the producer but also conditioned by the researcher's situationally embedded knowledge. This recognition of the complex nature of "social big data" forms the basis of the author's discussion of traditional criteria for information validation. The following chapter, by Jonas Stier, shares one of Andersson Schwarz's objectives, namely to problematize the idea that data and, in Stier's case, digital technologies are somehow clean, directly representational, and thus "objective." More precisely, Stier's chapter examines "inherent social and cultural biases" in educational and political discourses on digitization and digital innovations. Stier presents a typology of "discursive blind spots," including technocentrism and normativism, homoand heterocentrism, and ego- and ethnocentrism. The leading argument is that such biases and lacunae can be overcome by combining a set of integrative approaches or conducting research 
along interdisciplinary as well as intercultural and "intermethodological" lines.

Next follow two chapters that deal with visualization and visual terminology. The chapter by Julia Pennlert, Björn Ekström, and David Gunnarsson Lorentzen introduces a set of visual, or "teleoptical," metaphors for understanding and analyzing processes of computer-assisted readings. The chapter builds on three case studies of Instagram posts, Twitter conversations, and online scholarship in order to examine how metaphorical thinking inflects the research process. The picture suggested is that of "lenses" and "filters" between, on the one hand, the researcher and the instrument and, on the other, between the instrument and the object of study. In other words, the overall idea is to analyze how conceptual tools reciprocally shape the interfaces of digital objects and instruments, and intervene with the process of knowledge production. Approaching the visual sphere from another end, Karolina Uggla's chapter reviews the analytical terminology in the field of information visualization. The object of study is thus the words that name the process of turning data into images such as charts and graphs. "Infoviz" is both quantitatively and qualitatively permeating digital society. If the first concerns the sheer number of visualizations in such diverse domains as newsfeed and scholarship (the latter illustrated by Figures $3^{-6}$ in the preceding chapter), the second concerns the conceptual legacy of theorizing "information" or "data" as visual translations of numerical units. Uggla demonstrates how the field is broadly divided in subfields based on semiotic and "designerly" approaches that models the "same" visual objects somewhat differently. Such differences in how the visual object is conceptually modeled by terminological choices is particularly of note in Uggla's two “interpretative frameworks," dealing with social semiotics, and emotions and ethics, respectively.

Closing the first part, Amanda Wasielewski's chapter targets and questions the reluctance in the discipline of art history to employ digital methods. Wasielewski recognizes two factors as especially challenging. First, that the objects central to art history are images and that the methods for digital image analysis are more complicated than the methods for computational text analysis. Second, that there is today a lack of preexisting art historical 
data to study with digital methods (which may not be the case in the future). If these are the challenges Wasielewski identifies, her chapter also provides examples of studying "Internet art" and artists' digital traces in methodological frameworks that eschew simplifications such as digital methods on the one hand and traditional ones on the other: "it is useful to think of methodologies as techniques that can be combined and mixed together rather than camps ready to wage war on one another.”

\section{Legal and ethical dilemmas}

The second part gathers three chapters that deal with legal and ethical issues arising from the digital handling and processing of personal data in public and private administration and in higher education.

The first two chapters, by Stanley Greenstein and Cecilia Magnusson Sjöberg, both reject traditional legal approaches in favor of "proactive" (as distinct from reactive) law. This perspective, the authors argue, is better suited to dealing with the increasing use of digital technology in the contexts of, for instance, social security, social insurance, and other public administration. Greenstein especially points out that, since AI technology is presently put to a multiplicity of societal uses, it needs to be addressed broadly as a practice encompassing both the risk of manipulating human behavior and the legal function of protecting individuals. One of Greenstein's points is to learn from the cognitive sciences in order to properly analyze potential risks with AI. Together with perspectives from legal informatics, the insights from the cognitive sciences provide the author's basis for reassessing the "traditional legal science approach.” Magnusson Sjöberg's chapter focuses on issues of transparency in AI-based personal data processing, and highlights the need to have already implemented such considerations in the planning stages of systems design. Magnusson Sjöberg proceeds from making a distinction between her key term transparency and "openness," and explains the distinction's importance in the case of, for example, access to public sector information: public institutions can be governed by principles of openness but nevertheless fail to provide transparency due to insufficient access 
rights, or, if the legal rights are in place, insufficient implementation of them-hence the need to focus on legal proactivity.

Teresa Cerratto Pargman and Cormac McGrath's chapter highlights how higher education has more and more come to rely on big data in general and, in particular, on the methods and procedures known as learning analytics. The latter comprises a set of practices that relies on big data analysis in order to optimize and evaluate student learning and institutional management of learning environments. Based on a review of the scholarly literature within the field of learning analytics, the chapter examines the values and expectations attached to the use of big data in educational settings as well as its ethical implications. Above all, Cerratto Pargman and McGrath provide a discussion of the context-sensitivity of data-driven practices, the technical and ethical competences demanded to sustain them, and the risk of mistaking "data-driven" for "evidence-based."

\section{New objects - new approaches}

The third and last part comprises three chapters that demonstrate different approaches to new media objects: personal computers in the first chapter, YouTube shows in the second, and digital scholarship-or, rather, analog, printed, scholarship disseminated in digital form-in the third. In line with the last point, Johan Jarlbrink's and Christer Johansson's first two chapters also demonstrate the need for distinctions within the category of "new media" itself. Jarlbrink shows both how the life of a personal computer includes stages of "new" and "old," and how new hardware can very well include old software, whereas Johansson investigates how certain YouTube shows are both aligning themselves to and reforming old media such as radio and television.

More specifically, Jarlbrink's chapter examines personal computer biographies in order to trace not the content produced and saved by the previous owners but the micro history of $\log$ files, updates, and viruses that constitute an archive of the computers' own histories. Thereby, the author demonstrates the methods of digital forensics and media ethnography as the combinatory approach by which computer histories can be traced and contextualized. Of particular concern is the relation between micro 
and macro history. The forensic mapping of the time and space of computer use reveals, for instance, which owner saved most content on the space of the hard drive and how this changed over time. Jarlbrink points out that such results can, in the macro context of cultural heritage institutions, broadly serve to illuminate media use in the digital age.

Johansson examines the contemporary phenomenon of dialogue podcasts streaming live on YouTube, or, put differently, auditory media in combination with visual media. The chief examples are the politically controversial shows The Joe Rogan Experience and its Swedish counterpart Hur kan vi? Both are the targets of a far-reaching investigation of their medial nature and sociopolitical implications or questions that revolve around representation and communication. Method-wise, Johansson elaborates a tripartite approach that interconnects a semiotically based intermedial analysis, examining interactions between different types of modalities and signs, with a media-historical analysis that puts the YouTube shows in relation to the "orality" of earlier media. Lastly, the author intertwines these two threads with a communicational-theoretical analysis that attends to the digital platform as an infrastructure channeling speech into sociopolitical activity.

In the last chapter, Amanda Wasielewski and Anna Dahlgren develop a procedure for text mining art historical journals that displays problems of nonstandard formatting, notes instead of bibliographies, and layouts that change over time. In detailed steps, the authors provide a hands-on demonstration of the advantages and pitfalls of particular text mining tools. The authors make clear that the big issue in text mining a corpus of academic articles is how it can reassess historiographical presuppositions about, for instance, patterns of (supposedly) paradigmatic discourses. One way is to account for frequency of citations, which, the authors emphasize, requires both quantitative (total amount) and qualitative (distribution across different articles) considerations. Although the authors' case is confined to art historical journals, it is well illustrative of both practical problems and historiographical insights the procedure of text mining academic articles can encounter and benefit from in other branches of the humanities and the social sciences. 


\section{References}

Bal, Mieke. Travelling Concepts in the Humanities: A Rough Guide. Toronto: University of Toronto Press, 2002.

Bartscherer, Thomas, and Roderick Coover, eds. Switching Codes: Thinking Through Digital Technology in the Humanities and the Arts. Chicago, IL: University of Chicago Press, 20I I.

Benardou, Agiati, Erik Champion, Costis Dallas, and Lorna M. Hughes, eds. "Introduction: A Critique of Digital Practices and Research Infrastructures." In Cultural Heritage Infrastructures in Digital Humanities, I-I4. Abingdon: Routledge, 2018.

Berry, David M., and Anders Fagerjord. Digital Humanities: Knowledge and Critique in a Digital Age. Cambridge: Polity Press, 2017.

Bordalejo, Barbara, and Roopika Risam, eds. "Introduction.” In Intersectionality in Digital Humanities, I-8. Leeds: Arc Humanities Press, 20I9.

Borin, Lars. "About Språkbanken.” Språkbanken website. https:// spraakbanken.gu.se/eng/about-us/about-spr $\%_{3} \mathrm{C}_{3} \% \mathrm{~A}_{5} \mathrm{kbanken}$.

Brown, Kathryn, ed. The Routledge Companion to Digital Humanities and Art History. New York: Routledge, 2020.

Chicago University website. “The Digital Studies MA.” https://digital studies.uchicago.edu/about/digital-studies-ma.

Digital Human Sciences website. https://dhv.blogs.dsv.su.se.

Digital Studies/Le Champ numérique website. "About this Journal." https://www.digitalstudies.org.

Drucker, Johanna. Graphesis: Visual Forms of Knowledge Production. Cambridge, MA: Harvard University Press, 2014.

Dunn, Stuart, and Kristen Schuster, eds. "Research Methods in the Digital Humanities: General Introduction.” In Routledge International Handbook of Research Methods in Digital Humanities, I-9. London: Routledge, 2020.

Fuller, Matthew, ed. Software Studies: A Lexicon. Cambridge, MA: MIT Press, 2008.

Fuller, Matthew, and Andrew Goffey. Evil Media. Cambridge, MA: MIT Press, 20I 2. 
Gardiner, Eileen, and Ronald G. Musto. The Digital Humanities: A Primer for Students and Scholars. Cambridge: Cambridge University Press, 2015.

Gelfgren, Stefan, and Julia Pennlert. "En (digital) humaniora? Potential, dilemma och kritik." In Digital humaniora - Humaniora i en digital tid, edited by Per-Olof Erixon and Julia Pennlert, I I-26. Gothenburg: Daidalos, 2017.

Golub, Koraljka, Elisabet Göransson, Anna Foka, and Isto Huvila. "Digital Humanities in Sweden and Its Infrastructure: Status Quo and the Sine Qua Non." Digital Scholarship in the Humanities 35 , no. 3 (September 2020): 547-556.

Grau, Oliver, ed. Imagery in the $2 I^{\text {st }}$ Century. Cambridge, MA: MIT Press, 20I3.

Grusin, Richard. "The Dark Side of the Digital Humanities: Dispatches from Two Recent MLA Conventions.” In differences: A Journal of Feminist Cultural Studies 25, no. I (20I4): 79-92.

Hansen, Mark B. N. Feed-Forward: On the Future of Twenty-FirstCentury Media. Chicago, IL: University of Chicago Press, 2015.

Hayles, Katherine N. How We Think: Digital Media and Contemporary Technogenisis. Chicago, IL: University of Chicago Press, $20 \mathrm{I} 2$.

Huhtamo, Erkki, and Jussi Parikka, eds. Media Archaeology: Approaches, Applications, and Implications. Berkeley, CA: University of California Press, 20I I.

Kirschenbaum, Matthew. "What Is Digital Humanities and What's It Doing in English Departments?" In Debates in the Digital Humanities, edited by Matthew K. Gold, 3-I I. Minneapolis, MN: University of Minnesota Press, $20 \mathrm{I} 2$.

Klein, Julie Thompson. Interdisciplining Digital Humanities: Boundary Work in an Emerging Field. Ann Arbor, MI: University of Michigan Press, 20I 5 .

Kroker, Arthur, and Marilouise Kroker, eds. "Introduction.” In Critical Digital Studies, 3-35. Toronto: University of Toronto Press, 2013 [2008].

Loukissas, Yanni Alexander. All Data Are Local: Thinking Critically in a Data-Driven Society. Cambridge, MA: MIT Press, 2019. 
Northwestern University website. "Digital Studies Certificate Program.” https://sps.northwestern.edu/advanced-graduate-certificate /digital-studies.

Parikka, Jussi. What Is Media Archaeology? Cambridge: Polity, 20 I 2.

Poole, Alex H., and Deborah A. Garwood. "Digging into Data Management in Public-Funded, International Research in Digital Humanities." Journal of the Association for Information Science and Technology 7I, no. I (January 2020): 84-97.

Roth, Camille. "Digital, Digitized, and Numerical Humanities." Digital Scholarship in the Humanities 34, no. 3 (2019): 6I7-6I9.

Schriebman, Susan, Ray Siemens, and John Unsworth, eds. "Preface." In A New Companion to Digital Humanities. Chichester: John Wiley and Sons, 2016 [2004].

Stiegler, Bernard. “Call for Digital Studies.” Paper composed in $20 \mathrm{I} 2$. Digital Studies Network website. https://digital-studies.org/wp/call -for-digital-studies.

Svensson, Patrik. Big Digital Humanities: Imagining a Meeting Place for the Humanities and the Digital. Ann Arbor, MI: University of Michigan Press, 2016.

Svensson, Patrik, and David Theo Goldberg, eds. "Introduction" and "The Field of Digital Humanities." In Between Humanities and the Digital, I-I6. Cambridge, MA: MIT Press, 2015.

University of Maryland website. "Digital Studies in the Arts and Humanities.” https://dsah.umd.edu.

University of Pittsburgh website. "Digital Studies.” https://www.greens burg.pitt.edu/academics/majors-minors/digital-studies.

University of Wisconsin-Madison website. "Digital Studies.” https:// digitalstudies.wisc.edu.

Whalen, Ryan, ed. Computational Legal Studies: The Promise and Challenge of Data-Driven Research. Cheltenham: Edward Elgar Publishing, 2020.

Wildfeuer, Janina, Jana Pflaeging, John A. Bateman, Ognyan Seizov, and Chiao-I Tseng, eds. "Multimodality: Transdisciplinary Thoughts and the Challenge of Diversity - Introduction." In Multimodality: Disciplinary Thoughts and the Challenge of Diversity, 3-38. Berlin: De Gruyter, 2019. 